\title{
ERRATUM
}

\section{Erratum to: Seabed domes with circular depressions in the North Yellow Sea*}

\author{
WANG Bing (王冰 $)^{1,3}$, ZHANG Xin (张金金) ${ }^{1,2,3, * *}$, LUAN Zhendong (栾振东) ${ }^{1}$, \\ CHEN Chang'an (陈长安) $)^{1}$, YAN Jun (阎军) ${ }^{1}$ \\ ${ }^{\prime}$ CAS Key Laboratory of Marine Geology and Environment \& Center of Deep Sea Research, Institute of Oceanology, Chinese \\ Academy of Sciences, Qingdao 266071, China \\ ${ }^{2}$ Laboratory for Marine Geology, Qingdao National Laboratory for Marine Science and Technology, Qingdao 266061, China \\ ${ }^{3}$ University of Chinese Academy of Sciences, Beijing 100049, China
}

(c) Chinese Society for Oceanology and Limnology, Science Press and Springer-Verlag GmbH Germany, part of Springer Nature 2020

\section{Erratum to: https://doi.org/10.1007/s00343-019-7173-6}

The original version of this article unfortunately contained a mistake. Partial data in Fig.1 was incorrect. The corrected Fig. 1 is given below:

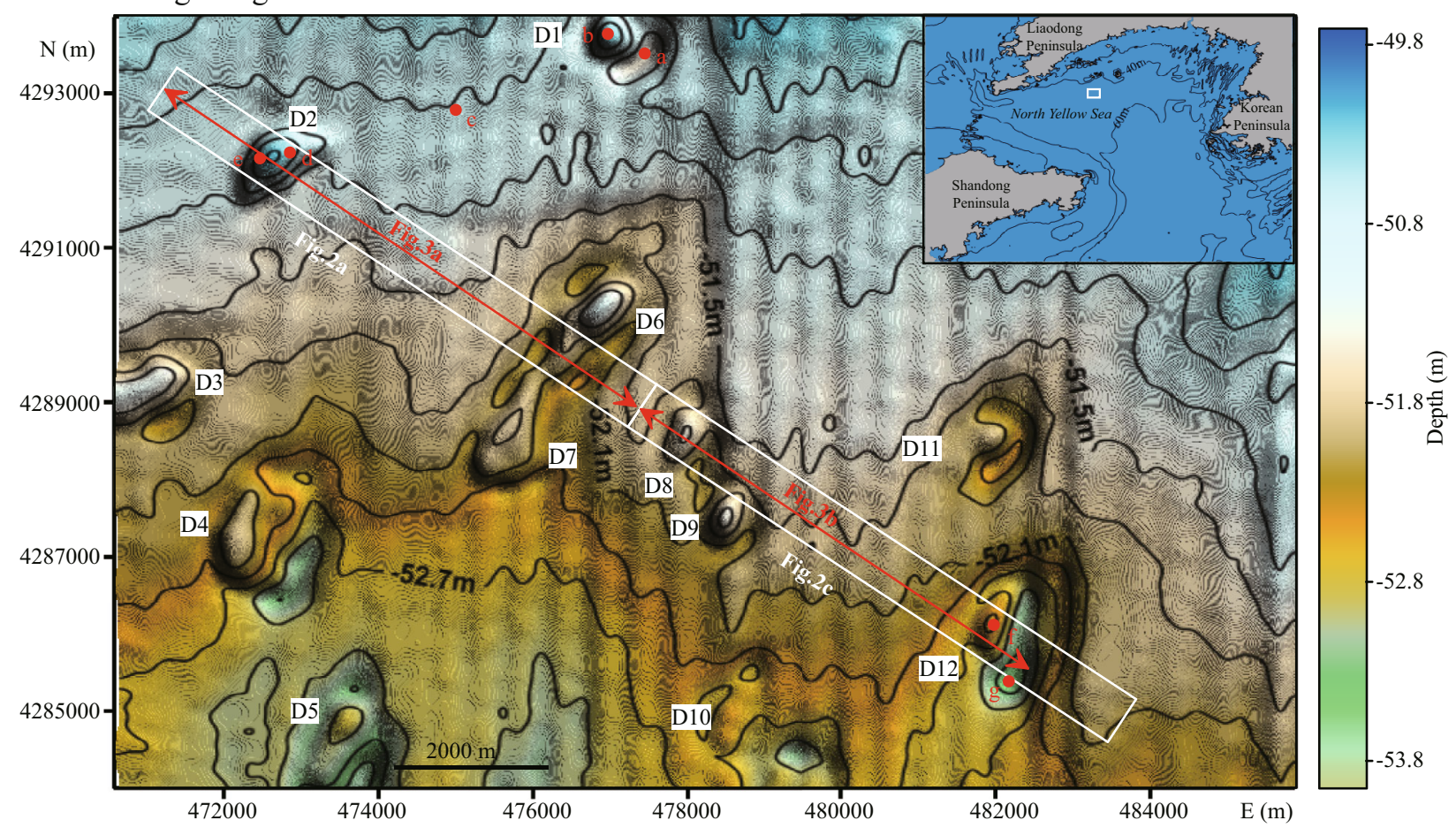

Fig.1 Location and bathymetric map of the study area

The solid red circles $(\mathrm{a}-\mathrm{g})$ show the locations of the gravity cores. The white rectangles and red lines with triangles delineate the side-scan sonar areas and the sub-bottom profile survey lines, respectively. The general location of the study area is indicated with a white box within the regional map (top right inset). Projection: UTM, WGS84, zone 51N.

The online version of the original article can be found at: https://doi.org/10.1007/s00343-019-7173-6.

* Supported by the Strategic Priority Research Program, CAS (No. XDA19060402), the NSFC-Shandong Joint Fund for Marine Science Research Centers (No. U1606401), the International Partnership for Innovative Team Program (No. 20140491526) from the Chinese Academy of Sciences, and the Taishan Scholar Project Funding (No. tspd20161007)

** Corresponding author: xzhang@qdio.ac.cn 